\title{
Evaluation of Reactive Induction Sintering as Manufacturing Route for Blended
}

\section{Elemental Ti-5Al-2.5Fe alloy}

\author{
M. T. Jia*, B. Gabbitas, L. Bolzoni \\ Waikato Centre for Advanced Materials, School of Engineering, The University of \\ Waikato, Private Bag 3105, 3240 Hamilton - New Zealand \\ ("Corresponding author: mingtujia@gmail.com)
}

\begin{abstract}
This work focuses on understanding the feasibility of using reactive induction sintering to obtain the Ti-5Al-2.5Fe alloy using $\mathrm{Ti}, \mathrm{Al}$ and $\mathrm{Fe}$ powders (i.e. via the blended elemental approach). For that, the powder compacts were induction sintered under various temperature/time combinations like $700-1250{ }^{\circ} \mathrm{C}$ and isothermal holding of 0-15 minutes. Compositional homogeneity, microstructure evolution and mechanical properties of the sintered $\mathrm{Ti}-5 \mathrm{Al}-2.5 \mathrm{Fe}$ alloy were investigated. It was found that by increasing sintering temperature and isothermal holding time, sintered Ti-5Al-2.5Fe components with homogeneous chemical distribution and Widmanstätten microstructure can be produced. The tensile strength increases with the sintering temperature/time reaching comparable values to the wrought alloy; however the residual porosity has a significant impact on the ductility of the alloy. The study demonstrates that reactive induction sintering is suitable to shorten the production route of blended elemental Ti alloys to be used in non-critical applications where ductility is not the main material's requirement.
\end{abstract}

Keywords: Titanium alloys; Powder metallurgy; Induction sintering 


\section{Introduction}

Ti-6Al-4V (composition are in wt.\% unless otherwise specified) is the workhorse titanium alloy which is still used in different critical applications, including products for the biomedical sector (Murr et al., 2009; Niinomi, 1998, 2002), due to its good corrosion resistance, excellent biocompatibility, low Young's modulus and high strength. However, the toxicity of $\mathrm{V}$ in Ti-6Al-4V has become a concern for implant materials (Choubey et al., 2004). V-free alpha-beta titanium alloys such as Ti-6Al$7 \mathrm{Nb}$ and $\mathrm{Ti}-5 \mathrm{Al}-2.5 \mathrm{Fe}$ have been developed to replace $\mathrm{Ti}-6 \mathrm{Al}-4 \mathrm{~V}$ for biomedical applications (Niinomi et al., 1996). Here, V is replaced by non-toxic $\mathrm{Nb}$ and $\mathrm{Fe}$. It has been suggested that $\mathrm{Ti}-6 \mathrm{Al}-7 \mathrm{Nb}$ and $\mathrm{Ti}-5 \mathrm{Al}-2.5 \mathrm{Fe}$ alloys are good alternatives to replace Ti-6Al-4V in terms of corrosion resistance, biocompatibility and mechanical properties (Choubey et al., 2004). Compared to the addition of expensive $\mathrm{Nb}$ in $\mathrm{Ti}$ $6 \mathrm{Al}-7 \mathrm{Nb}$ alloy, a more cost effective way is to synthesize Ti-5Al-2.5Fe alloy using $\mathrm{Fe}$ to replace V. Although mainly developed for medical prosthesis, the Ti-5Al-2.5Fe alloy could potentially replace Ti-6Al-4V in other non-critical application as both are alpha-beta alloys and have fairly comparable mechanical behaviour.

Powder metallurgy of titanium (Ti) and $\mathrm{Ti}$ alloys has received much attention for producing near net shape components for a variety of applications (Abkowitz et al., 2011; Froes et al., 2004) and two approaches are commonly used. The first utilises expensive pre-alloyed powders whose range of commercial compositions is rather limited, while the second involves the mixing of different starting powders (i.e. blended elemental approach). In comparison to the pre-alloyed approach, blended elemental is a promising way to produce lower cost $\mathrm{Ti}$ alloy components without limitations in terms of chemistry of the material. From literature, the blended elemental approach has been used to produce the Ti-6Al-7Nb and Ti-5 Al-2.5Fe alloys 
using $\mathrm{Ti}, \mathrm{Al}, \mathrm{Nb}$ and $\mathrm{Fe}$ elemental powders using hot pressing and vacuum sintering, respectively (Henriques et al., 2003; Siqueira et al., 2009). The microstructural studies performed in the previously mentioned works (Henriques et al., 2003; Siqueira et al., 2009) confirmed that a homogeneous alloying element distribution is achieved in both alloys when sintered at $1400{ }^{\circ} \mathrm{C} / 1 \mathrm{~h}$ and $1200{ }^{\circ} \mathrm{C} / 2 \mathrm{~h}$ for the Ti-6Al-7Nb and Ti-5Al2.5Fe alloys, respectively. As a result, a coarse plate-like $\alpha$ structure and intergranular $\beta$ structure were obtained in both alloys. In the best knowledge of the authors, no studies about the use of reactive induction sintering to manufacture these alloys are available in the current literature, in particular lacking tensile properties of sintered Ti-5Al-2.5Fe alloy, which is important for its industrial application. In order to prevent severe grain growth and to shorten the sintering time, field-assisted sintering techniques, which include microwave sintering (Luo et al., 2011), plasma spark sintering (SPS) (Zadra et al., 2008) and induction sintering (Dewidar, 2010; Jia and Gabbitas, 2015), are receiving much attention. Among these techniques, induction sintering has been previously studied to fabricate Fe-based materials (Çavdar and Atik, 2014; Hermel et al., 1980; Krumphold et al., 1984; Salak et al., 1981) and hardmetals (Kim et al., 2008; Shon et al., 2009; Shon et al., 2010; Shon et al., 2013). Literature confirmed the high heating rates, permitting rapid sintering of the parts, which is what this work is focused on.

The reactions occurring between solid/liquid aluminium (Al) and solid Ti have been widely investigated (Luo and Acoff, 2004; Mirjalili et al., 2013; Paul et al., 2014; Paul et al., 2004; $\mathrm{Xu}$ et al., 2006). In the Ti/Al couple, the formation of the $\mathrm{Al}_{3} \mathrm{Ti}$ intermetallic via an exothermic reaction is the only event at low temperature (700$1000^{\circ} \mathrm{C}$ ) (Sujata et al., 1997). Accordingly, Ti aluminides are rapidly formed when elemental $\mathrm{Ti}$ and $\mathrm{Al}$ powders are used (Lee, 1998; Sun et al., 2015; Wenbin et al., 
2005) and the formation of $\mathrm{Al}_{3} \mathrm{Ti}$ by the reaction of the $\mathrm{Al}$ atoms with Ti results in the swelling of the powder compact (Böhm et al., 2001; Savitskii, 2009). This was verified via dilatometric studies of Ti-Al powder mixture during sintering (Savitskii, 2009). Then the phases $\mathrm{Ti}_{3} \mathrm{Al}, \mathrm{TiAl}, \mathrm{TiAl}_{2}$ are formed by reactions between $\mathrm{Ti}$ and $\mathrm{Al}_{3} \mathrm{Ti}$ in the absence of $\mathrm{Al}$ (Paul et al., 2004). However, no knowledge is available when processing $\mathrm{Ti}$ alloys such as $\mathrm{Ti}-5 \mathrm{Al}-2.5 \mathrm{Fe}$ alloy by means of reactive induction sintering and it is therefore thoroughly analysed in this study.

The main aim of this work is to study the applicability of reactive induction sintering for the production of the blended elemental Ti alloys, and in particular of the Ti-5Al2.5Fe alloy. Emphasis is put on lowering the production cost (e.g. short processing time) and to limit grain growth induced by the sintering step as reactive induction sintering is used to rapidly sinter powder compacts at a high temperature with short isothermal holding time. Apart from proving the influence of this alternative processing route on porosity, microstructural evolution and mechanical behaviour of the sintered material, the study considers an in-depth analysis of the formation of transient intermetallic phases during sintering aiming to understand their formation and effect on the behaviour of the sintered material.

\section{Experimental procedure}

Three elemental powders ( $\mathrm{Ti}, \mathrm{Al}$ and $\mathrm{Fe}$ ) were used in this study. Commercially pure Ti powder (Particle size $<75 \mu \mathrm{m},>99.5 \%$ purity) produced using the hydrogenationdehydrogenation $(\mathrm{HDH})$ process was purchased from Goodfellow Ltd. Pure Al powder (Particle size: $45-75 \mu \mathrm{m},>99.7 \%$ purity) was supplied by ECKA Granules

Ltd. Carbonyl iron powder (Particle size: 5-9 $\mu \mathrm{m},>99 \%$ purity) was acquired from Sigma-Aldrich Ltd. The interstitial element content $(\mathrm{O}, \mathrm{N}$ and $\mathrm{H})$ of the raw powders 
are listed in Table 1 and are relevant as interstitials affect the mechanical performances of Ti alloys (Donachie, 2000). Specifically, in the case of CP Ti, the powder can be classified as grade 3 as the $\mathrm{O}$ content is lower than $0.35 \%$.

Table 1. Interstitial contents $(\mathrm{O}, \mathrm{N}$ and $\mathrm{H})$ of the raw powders.

\begin{tabular}{|c|c|c|c|}
\hline Raw powder & $\mathbf{O}[\mathbf{\%}]$ & $\mathbf{N}[\boldsymbol{\%}]$ & $\mathbf{H}[\boldsymbol{\%}]$ \\
\hline $\mathrm{Ti}$ & 0.27 & 0.01 & 0.00019 \\
\hline $\mathrm{Al}$ & 0.56 & $<0.01$ & 0.00003 \\
\hline $\mathrm{Fe}$ & 0.32 & $<0.01$ & 0.00022 \\
\hline
\end{tabular}

The right amount of raw powders were blended for 24 hours using a two-roll mill to produce a homogeneous $\mathrm{Ti}-5 \mathrm{Al}-2.5 \mathrm{Fe}$ powder mixture. $50 \mathrm{~g}$ powder mixtures were pressed into $40 \mathrm{~mm}$ diameter cylindrical compacts at room temperature using a pressure of $780 \mathrm{MPa}$. The compacts were then reactive induction sintered under argon protective atmosphere (oxygen content $<200 \mathrm{ppm}$ ) and cooled to room temperature under argon. The heating rate was around $450{ }^{\circ} \mathrm{C} / \mathrm{min}$. The temperature during sintering was recorded using a K-type thermocouple, which was placed in the centre region of top surface of cylindrical compact, and the temperature was controlled by adjusting the power input from a generator to achieve a homogeneous temperature distribution. Although electrical conductivity can vary with the density distribution of compact (Simchi and Danninger, 2000), in this study it was assumed to be constant due to the high level of relative green density achieved during compaction.

The main study was performed keeping the sintering temperature constant at $1250{ }^{\circ} \mathrm{C}$, which is one of the most commonly employed for sintering Ti alloys (Fujita et al., 1996; Liu et al., 2006; Wei et al., 2003), and varying the isothermal holding times from 0 ' to $15^{\prime}$ (every 5'). However, to complete this work with the study of the 
formation of potential transient intermetallic phases, some samples were also sintered at $700{ }^{\circ} \mathrm{C}$ without isothermal holding.

Green and sintered densities of the compacts were measured using their mass-tovolume ratio and via the gravimetric method, respectively. Differential thermal analysis (DTA) was performed on the powder mixture at a heating rate of $10{ }^{\circ} \mathrm{C} / \mathrm{min}$ under argon protective atmosphere using a TA Instrument SDT 2960. X-ray diffraction (XRD) using $\mathrm{CuK}_{\alpha}$ radiation source $\left(2 \theta=20-90^{\circ}\right.$ and scanning rate of 2 $\%$ min) was carried out to confirm the phase constituting the sintered alloys and the formation/dissolution of any potential intermetallic phase. Metallographic preparation of the samples included grinding, polishing and etching by means of Kroll's reagent ( $2 \mathrm{ml} \mathrm{HF}, 6 \mathrm{ml} \mathrm{HNO}_{3}$ and $92 \mathrm{ml}$ distilled water) to reveal their microstructure. Pore size was measured on series of images captured by optical micrographs (Olympus BX60) on non-etched samples using Image-Pro Plus 6.0 software. Microstructure analysis was conducted on a Hitachi S4700 scanning electrical microscope (SEM) equipped with an energy dispersive X-ray spectrometer (EDS), used to check the distribution of alloying elements. The interstitial content $(\mathrm{O}, \mathrm{N}$ and $\mathrm{H})$ was measured using the combustion method (LECO). At least three flat dog-bone shaped tensile test specimens with cross-sectional dimensions of $2 \times 2 \mathrm{~mm}^{2}$ were cut from sintered powder compacts. An Instron 33R4204 universal testing machine was used to perform the tensile testing at a strain rate of $1 \times 10^{-4} \mathrm{~s}^{-1}$ at room temperature. The strain was measured using an extensometer with a gauge length of $10 \mathrm{~mm}$. The plane porosity was measured on fractographic images, taken at the SEM, using the dedicated ImagePro Plus 6.0 software.

\section{Results}


In this study the density of the wrought Ti-5Al-2.5Fe alloy (i.e. $4.45 \mathrm{~g} / \mathrm{cm}^{3}$ ) was used as theoretical density of the powder metallurgy alloy studied as this value does not differ significantly from the one calculated using the rule of mixture. As some intermetallic phases form, but they are transient and their fraction is low, their effect on the density of the sintered materials was not considered. The average density of green powder compacts was $89.7 \pm 1.0 \%$ whilst the density of a Ti-5Al-2.5Fe powder compact sintered at $700{ }^{\circ} \mathrm{C}$ without isothermally holding was $87.6 \%$ indicating that there was some swelling in Ti-5Al-2.5Fe compacts. Form literature, this swelling of the compacts is due the reaction between the Ti and Al powders (Böhm et al., 2001). From Figure 1, it is evident that the density of sintered Ti-5Al-2.5Fe powder compacts increased gradually (from $88.8 \%$ to $92.1 \%$ ) with increasing the isothermal holding time from $0^{\prime}$ to $15^{\prime}$ at $1250^{\circ} \mathrm{C}$.

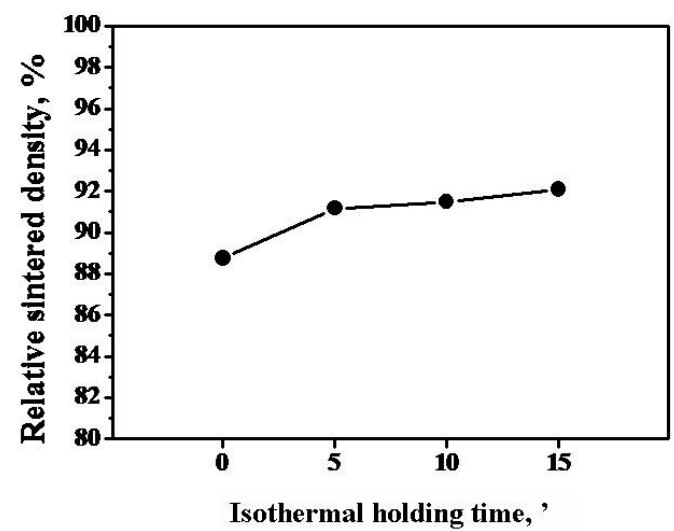

Figure 1. Variation of the relative density of the Ti-5Al-2.5Fe alloy reactive induction sintered at $1250{ }^{\circ} \mathrm{C}$ versus holding time.

The results of the characterisation of the porosity left by the reactive induction sintering processing of the blended elemental Ti-5Al-2.5Fe samples are shown in Figure 2 where it can be seen that the samples sintered at $700{ }^{\circ} \mathrm{C}$ (Figure 2 a) have irregular residual pores. The largest pores are the voids formed by the transient $\mathrm{Al}$ 
melt as their size is similar to that of the Al powder particles used and the smaller ones are from the poor consolidation as a consequence of the low sintering temperature.
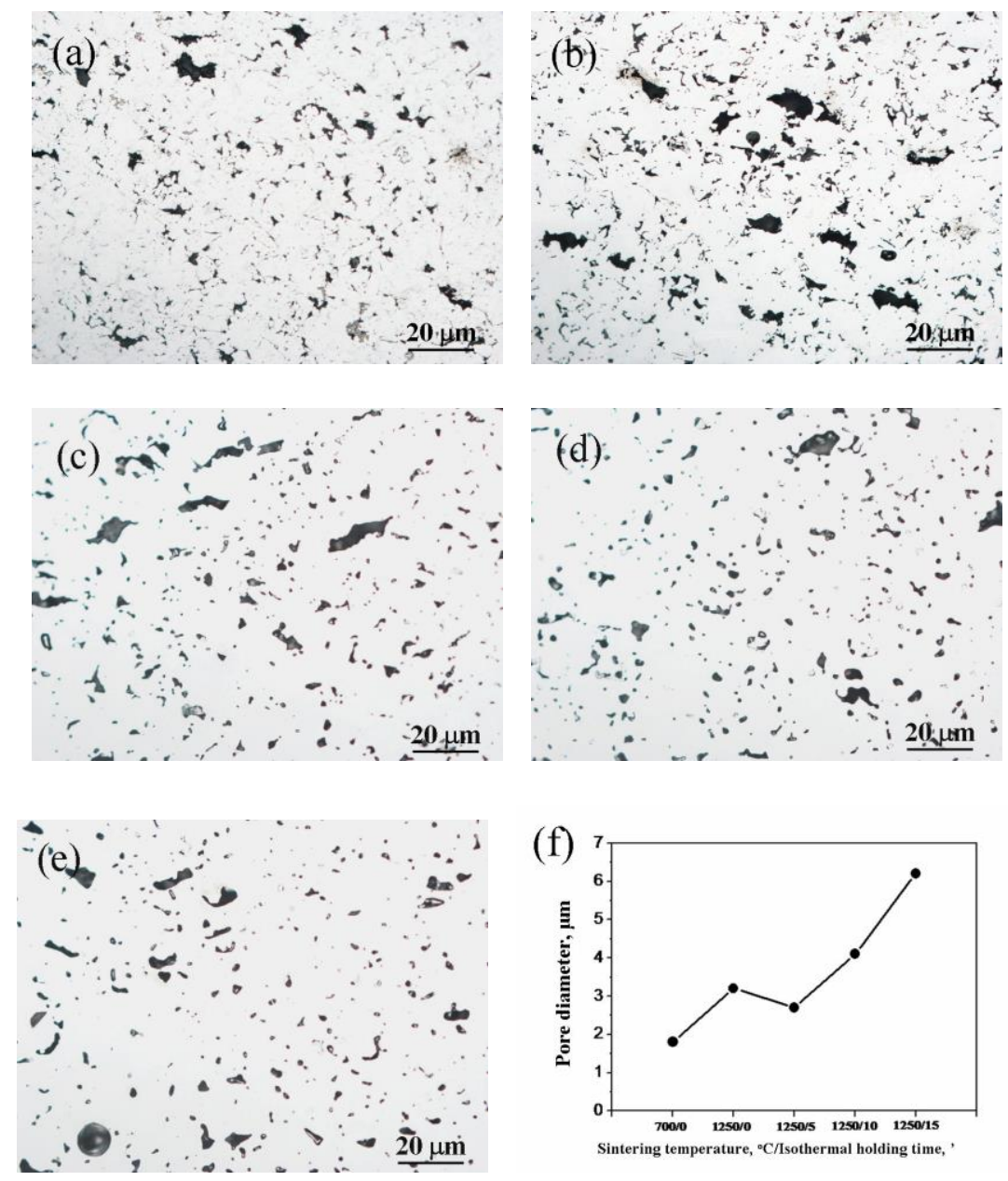

Figure 2. Optical micrographs showing the residual porosity of the Ti-5 Al-2.5Fe alloy reactive induction sintered at: (a) $700{ }^{\circ} \mathrm{C} /$ no holding, (b) $1250{ }^{\circ} \mathrm{C} /$ no holding, (c) $1250{ }^{\circ} \mathrm{C} / 5^{\prime}$, (d) $1250{ }^{\circ} \mathrm{C} / 10^{\prime}$, (e) $1250{ }^{\circ} \mathrm{C} / 15^{\prime}$, and (f) variation of the pore size with the processing parameters.

By increasing the sintering temperature to $1250{ }^{\circ} \mathrm{C}$, without isothermally holding, the size of the smaller pores increase and the shape of all residual pores starts to become more rounded (Figure $2 \mathrm{~b}$ ). As the isothermal holding time during sintering increases, the residual pores become predominantly spherical (Figure $2 \mathrm{c}-\mathrm{e}$ ). The quantification 
of the average pore size, shown in Figure $2 \mathrm{f}$ ), reveals that the pore size increases from $1.8 \mu \mathrm{m}$ to $3.2 \mu \mathrm{m}$ as the sintering temperature is increased from $700^{\circ} \mathrm{C}$ to $1250^{\circ} \mathrm{C}$, then slightly decreased to $2.7 \mu \mathrm{m}$ when the isothermal holding time at $1250^{\circ} \mathrm{C}$ was increased to 5 minutes. Longer holding time caused the average pore size to gradually increase as a result of pore coarsening.

A close analysis of the DTA results, heating curve of Ti-5Al-2.5Fe powder mixture shown in Figure 3, reveals that between $600{ }^{\circ} \mathrm{C}$ and $700{ }^{\circ} \mathrm{C}$ an exothermic peak is starting to appear at the onset temperature of $625^{\circ} \mathrm{C}$. This exothermic peak is overshadowed by the appearance of an endothermic peak from $660{ }^{\circ} \mathrm{C}$ to $668{ }^{\circ} \mathrm{C}$. The exothermic peak is due to the solid state reaction between the $\mathrm{Al}$ and the Ti powder particles, most likely to form $\mathrm{Al}_{3} \mathrm{Ti}$ and subsequently $\mathrm{Ti}_{3} \mathrm{Al}$, whereas the superimposed endothermic peak is related to the melting of $\mathrm{Al}$ (Welham, 1998). From the DTA curves of Figure 3, it can also be seen that no peaks connected to the formation of Ti-Fe intermetallic phases, which would be expected to form around $1100{ }^{\circ} \mathrm{C}$, were not detected. This is either indicating that no Fe-based intermetallic are formed or, if they form in small amount, the thermodynamic signal associated with their formation is below the detection limit of the equipment. The XRD patterns reported in Figure 4 show that the Ti-5Al-2.5Fe powder compacts sintered at $700{ }^{\circ} \mathrm{C}$ have mainly $\alpha$ phase with a small amount of $\mathrm{Ti}_{3} \mathrm{Al}$ phase whereas the phases detected in the Ti-5 Al-2.5Fe alloy sintered at $1250{ }^{\circ} \mathrm{C}$ are $\alpha$ phase and a small amount of transformed $\beta$ phase, regardless of the actual holding time. 


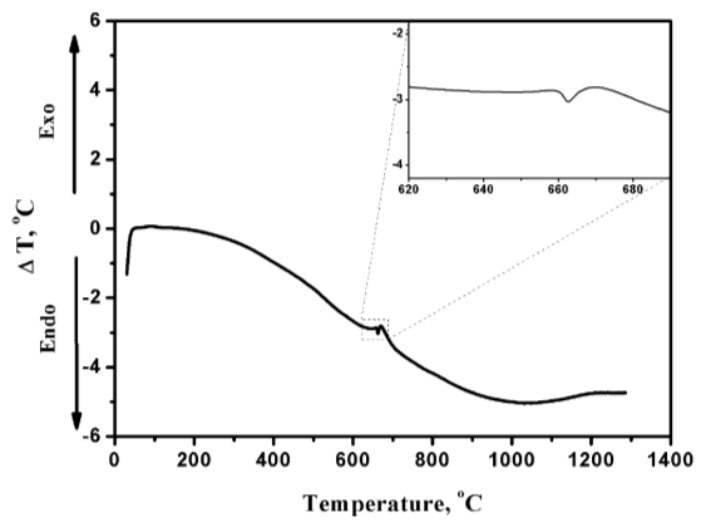

Figure 3. DTA curve of the Ti-5Al-2.5Fe powder mixture.

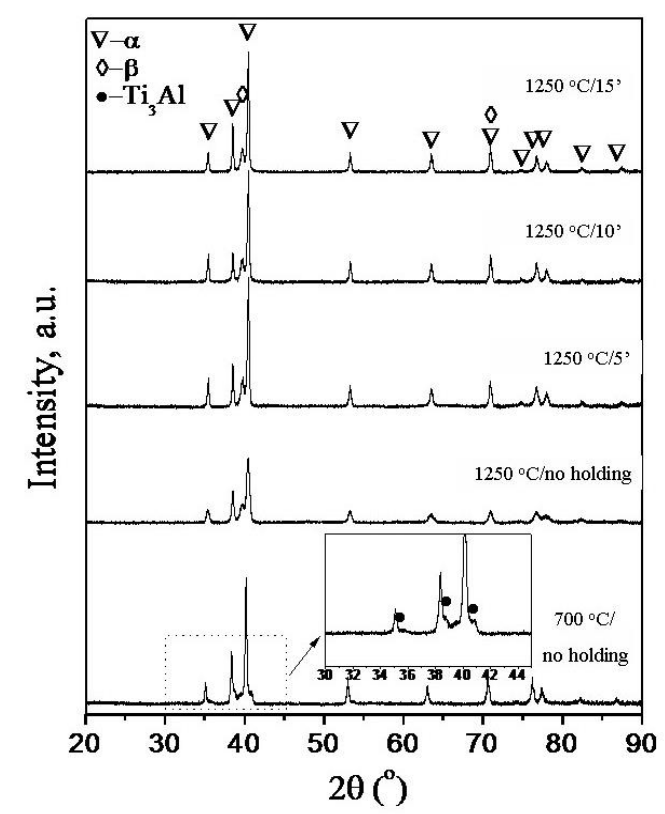

Figure 4. XRD patterns of the reactive induction sintered Ti-5Al-2.5Fe alloy.

The microstructural analysis of the Ti-5Al-2.5Fe alloy sintered at $700{ }^{\circ} \mathrm{C}$ reveals an incomplete Widmanstätten microstructure (Figure 5 a). When the sintering temperature is initially increased to $1250{ }^{\circ} \mathrm{C}$ (Figure $5 \mathrm{~b}$ ), the microstructure of the material is completely Widmanstätten. With an isothermal holding time of 5-15', there is no change in the microstructure as shown in Figure $5 \mathrm{c}-\mathrm{e}$ ). 

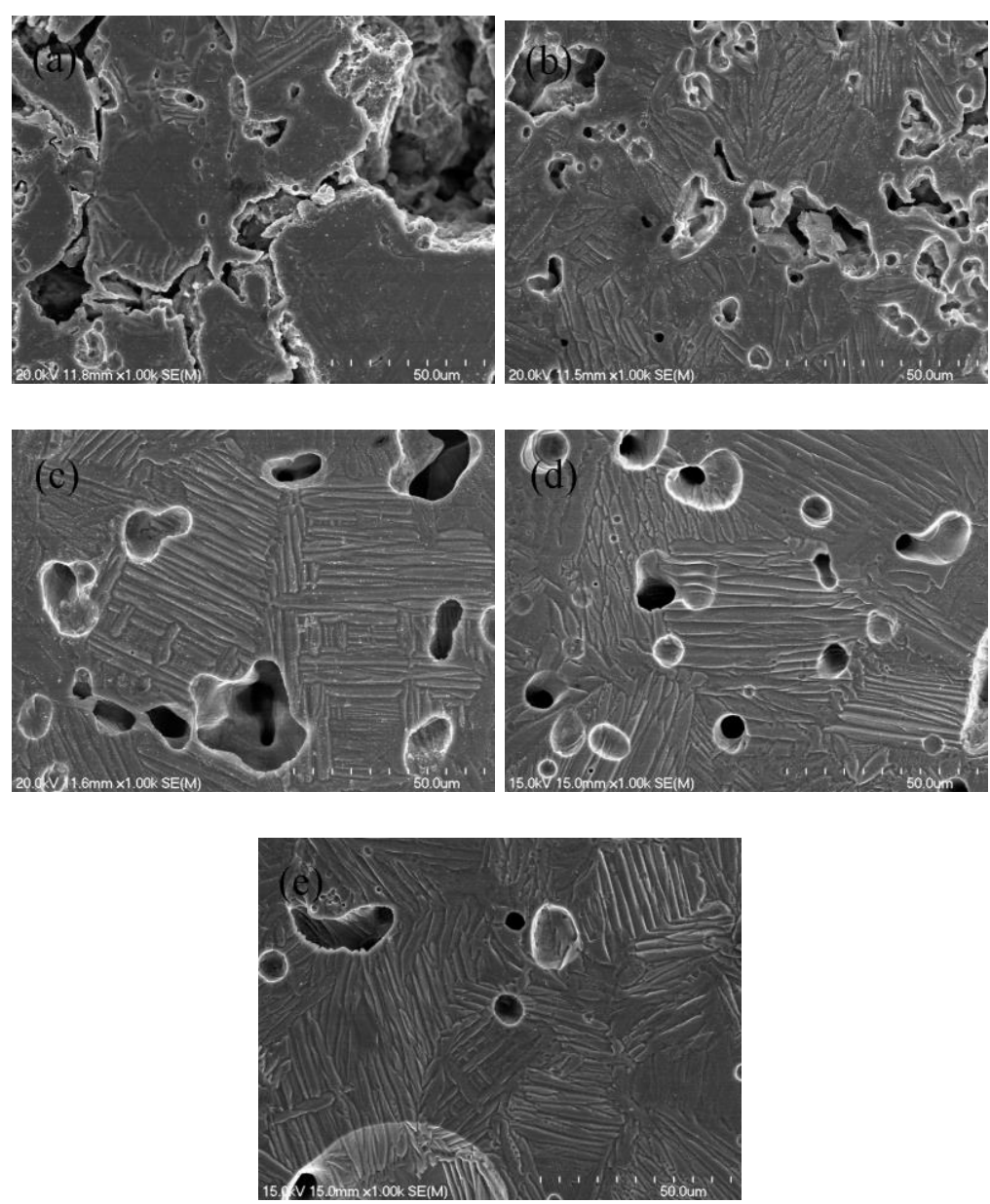

Figure 5. Details of the microconstituents of the Ti-5Al-2.5Fe alloy reactive induction sintered at: (a) $700{ }^{\circ} \mathrm{C} /$ no holding, (b) $1250{ }^{\circ} \mathrm{C} /$ no holding, (c) $1250{ }^{\circ} \mathrm{C} / 5$, (d) $1250^{\circ} \mathrm{C} / 10^{\prime}$, and (e) $1250{ }^{\circ} \mathrm{C} / 15^{\prime}$.

However, the achievement of the Widmanstätten microstructure does not necessary indicate that the distribution of alloying elements (i.e. $\mathrm{Al}$ and $\mathrm{Fe}$ ) is fully homogeneous. To ascertain the homogeneity of the distribution of $\mathrm{Ti}, \mathrm{Al}$ and $\mathrm{Fe}$ in the sintered compacts, EDS elemental mapping was carried out and the results are shown in Figure 6. It can be seen that there is not a uniform distribution of $\mathrm{Ti}, \mathrm{Al}$ and $\mathrm{Fe}$ after sintering at $700{ }^{\circ} \mathrm{C}$ without isothermally holding. This is evidenced by the $\mathrm{Al}-$ and $\mathrm{Fe}-$ rich regions in Figure 6 a). When the sintering temperature is increased from $700{ }^{\circ} \mathrm{C}$ to $1250{ }^{\circ} \mathrm{C}$, the $\mathrm{Ti}$ and $\mathrm{Fe}$ distribution become more homogenous, but Figure $6 \mathrm{~b}$ ) 
shows that the Al distribution is not completely homogeneous. A complete homogeneous distribution of the three elements is achieved by increasing the isothermal holding time to $5^{\prime}$ at $1250^{\circ} \mathrm{C}$, as shown in Figure $6 \mathrm{c}$ ), which is further obtained for longer isothermal holding time (Figure $6 \mathrm{~d}-\mathrm{e}$ ).

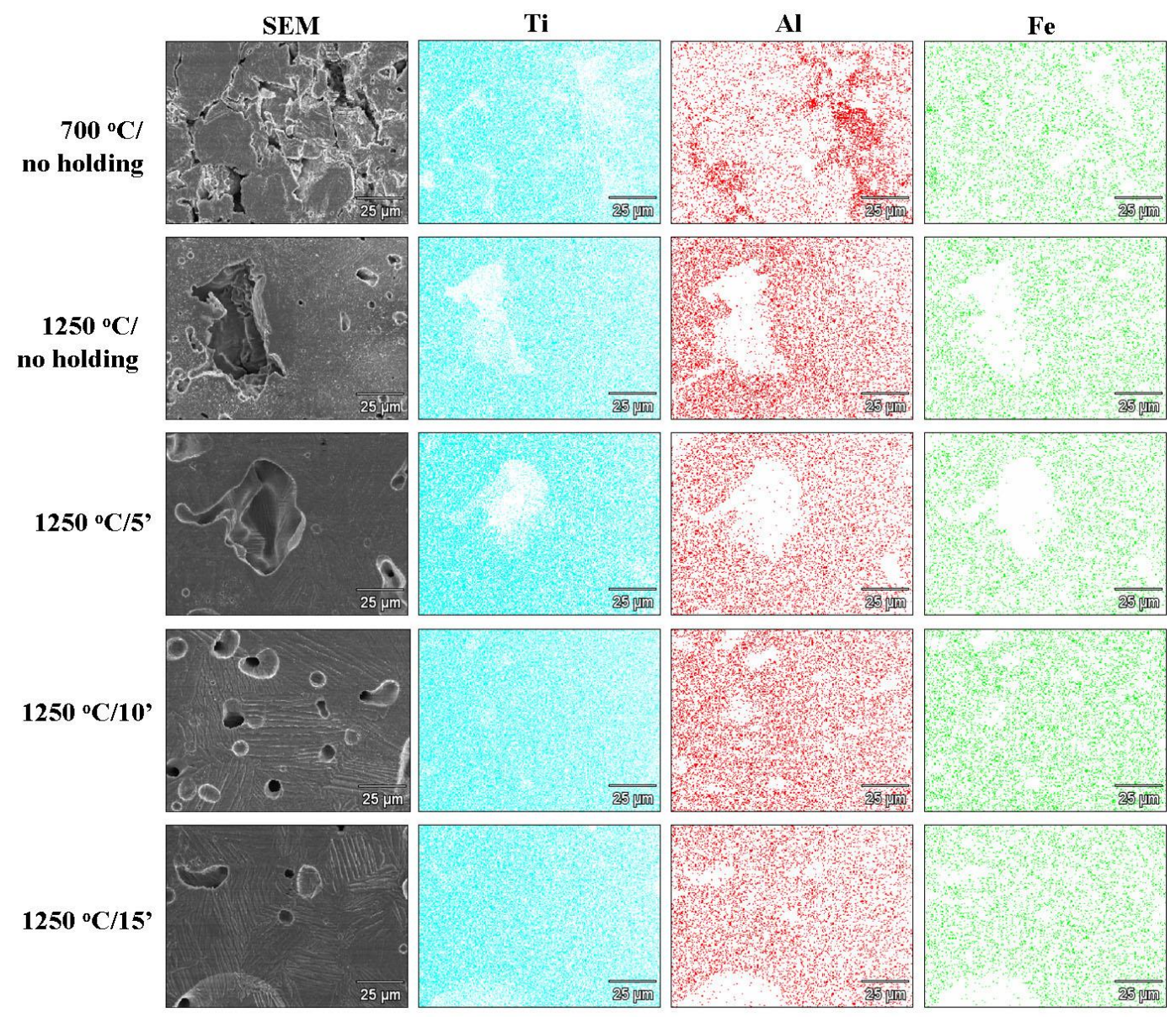

Figure 6. SEM images and corresponding $\mathrm{Ti}, \mathrm{Al}$ and $\mathrm{Fe}$ elemental maps of the reactive induction sintered Ti-5Al-2.5Fe alloy.

The characteristic engineering stress-strain curves of the reactive induction sintered Ti-5Al-2.5Fe alloy displayed in Figure 7 show that the material fails without plastic deformation when sintered without holding time independently of the temperature (i.e. $700{ }^{\circ} \mathrm{C}$ or $1250{ }^{\circ} \mathrm{C}$ ); however, a minimum holding time of $5^{\prime}$ at $1250^{\circ} \mathrm{C}$ changes the deformation mode of the sintered alloy. The curves also indicate that the higher the 
sintering temperature and the longer the holding time, the better the mechanical properties in agreement with current sintering theories (German, 1996). Specifically, both tensile strength and elongation increase when the sintering temperature is raised from $700{ }^{\circ} \mathrm{C}$ to $1250{ }^{\circ} \mathrm{C}$, or when the compact is hold at maximum temperature; however, no significant effect is detected after an holding time of 10'. This behaviour is a direct consequence of the size/shape of the residual pores and microconstituents of the sintered alloys. Consistently with the tensile behaviour, fractographic analysis (results also shown in Figure 7) confirms that the alloys sintered without holding time mainly have a cleavage type of fracture. By increasing the isothermal holding time to $5-15^{\prime}$ at $1250{ }^{\circ} \mathrm{C}$, the fracture mode changes to a mixture of cleavage and ductile dimples where the relative amount of ductile fracture zones proportionally increase along with the isothermal holding.
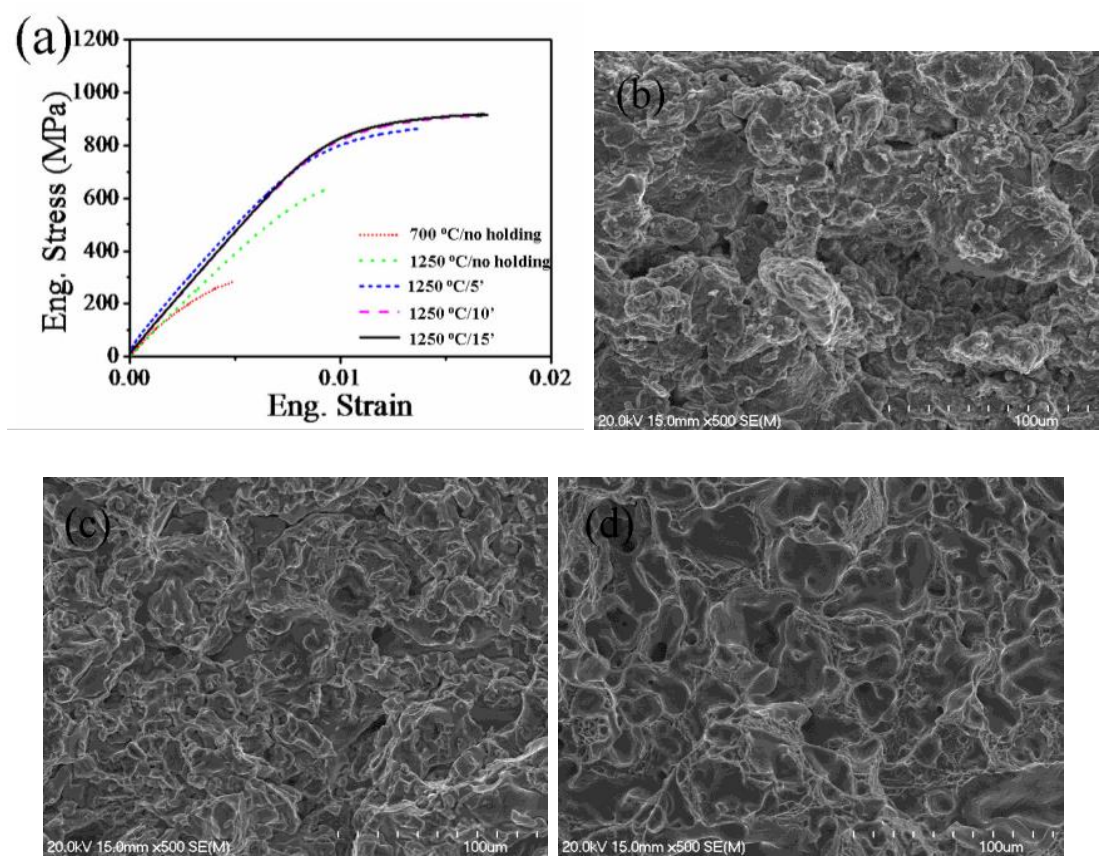

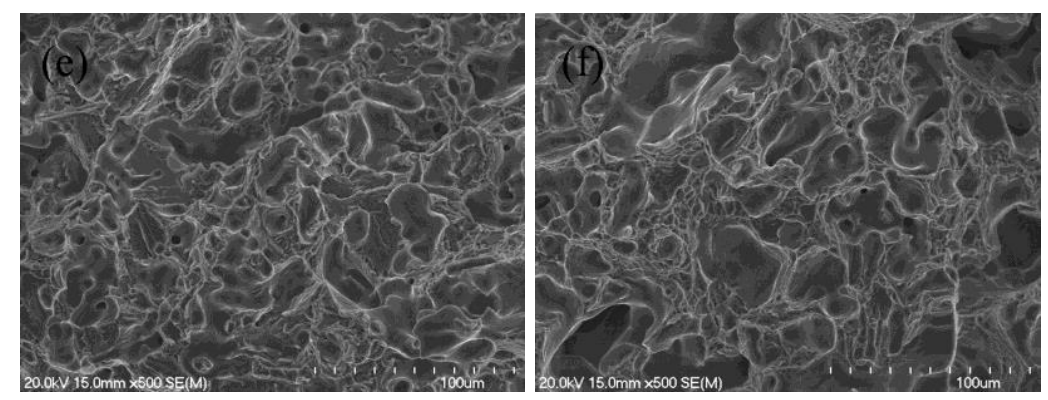

Figure 7. Characteristic engineering stress-strain curves of the reactive induction sintered Ti-5Al-2.5Fe alloy (a), and respective fracture morphology: (b) $700{ }^{\circ} \mathrm{C} /$ no holding, (c) $1250{ }^{\circ} \mathrm{C} /$ no holding, (d) $1250{ }^{\circ} \mathrm{C} / 5^{\prime}$, (e) $1250{ }^{\circ} \mathrm{C} / 10^{\prime}$, and (f) $1250{ }^{\circ} \mathrm{C} / 15^{\prime}$.

\section{Discussion}

\subsection{Analysis of transient phases and homogeneity during reactive induction sintering}

The microstructural evolution of Ti-5Al-2.5Fe and Ti-6Al-7Nb produced by a blended elemental approach has been previously studied using different temperatures (Henriques et al., 2003; Siqueira et al., 2009). In these studies more attention was paid to the dissolution of $\mathrm{Fe}$ and $\mathrm{Nb}$ at various sintering temperatures. However, the dissolution of $\mathrm{Al}$ has not been studied in detail. In the current study, $\mathrm{Al}$ and $\mathrm{Fe}$ powders were simultaneously added to Ti to produce the Ti-5Al-2.5Fe alloy. So the diffusion of both elemental $\mathrm{Al}$ and $\mathrm{Fe}$ into a $\mathrm{Ti}$ powder matrix would occur concurrently at elevated temperature during sintering. It is assumed that due to the low $\mathrm{Al}$ and $\mathrm{Fe}$ content in a Ti-5Al-2.5Fe alloy, any diffusion between $\mathrm{Al}$ and $\mathrm{Fe}$ powders can be ignored.

The binary Ti-Al phase diagram gives the equilibrium phases for different $\mathrm{Al}$ contents (Murray, 1988) and they are $\alpha-\mathrm{Ti}, \mathrm{Ti}_{3} \mathrm{Al}, \mathrm{TiAl}, \mathrm{TiAl}_{2}, \mathrm{Al}_{3} \mathrm{Ti}$ and $\mathrm{Al}$. However, in a TiAl diffusion couple, it has been verified that these phases do not appear simultaneously (Luo and Acoff, 2004; Mirjalili et al., 2013; Paul et al., 2014; Xu et al., 
2006). At first, $\mathrm{Al}_{3} \mathrm{Ti}$ is the only phase forming between $\mathrm{Al}$ and $\mathrm{Ti}$ in a $\mathrm{Ti}-\mathrm{Al}$ diffusion couple when the temperature is increased. As the thickness of the $\mathrm{Al}_{3} \mathrm{Ti}$ phase grows, a Ti-Al 3 Ti diffusion couple is formed instead of a Ti-Al diffusion couple (Mirjalili et al., 2013). Then, with a further increment of the temperature, $\mathrm{Ti}_{3} \mathrm{Al}, \mathrm{TiAl}, \mathrm{TiAl}_{2}$ form in a $\mathrm{Ti}-\mathrm{Al}_{3} \mathrm{Ti}$ diffusion couple (Paul et al., 2004). This can be expressed as follows:

$$
\begin{aligned}
& 2 \mathrm{Ti}+3 \mathrm{Al} \rightarrow \mathrm{Ti}+\mathrm{Al}_{3} \mathrm{Ti} \\
& 4 \mathrm{Ti}+2 \mathrm{Al}_{3} \mathrm{Ti} \rightarrow \mathrm{Ti}_{3} \mathrm{Al}+2 \mathrm{TiAl}_{2}+\mathrm{TiAl}
\end{aligned}
$$

The in-depth EDS composition analysis of Al-rich regions in the samples reactive induction sintered at $700{ }^{\circ} \mathrm{C}$ show that $\mathrm{TiAl}$ and $\mathrm{Ti}_{3} \mathrm{Al}$ phases are formed in the $\mathrm{Al}-$ rich regions, but no $\mathrm{TiAl}_{2}, \mathrm{Al}_{3} \mathrm{Ti}$ and $\mathrm{Al}$ phases are present (Figure 8 a). This means that at the sintering temperature of $700{ }^{\circ} \mathrm{C}$, which is higher than the onset temperature of the reaction between $\mathrm{Ti}$ and $\mathrm{Al}$ in the $\mathrm{Ti}-5 \mathrm{Al}-2.5 \mathrm{Fe}$ powder mixture $\left(625^{\circ} \mathrm{C}\right)$, reaction (1) already occurred and reaction (2) is taking place. According to the peaks of the DTA heating curve of Figure 3, the exothermal solid state reaction starts but is then eclipsed by the melting of $\mathrm{Al}$, so that the liquid $\mathrm{Al}$ penetrate into the voids among the Ti powder particles, by capillary force, coating them. Subsequently, the reaction between solid $\mathrm{Ti}$ and liquid $\mathrm{Al}$ occurs leading to the formation of $\mathrm{Ti}$ aluminides such as $\mathrm{TiAl}$ and $\mathrm{Ti}_{3} \mathrm{Al}$, which was actually detected via XRD (Figure 4). The reaction sequence described is consistent with a previous study about sintering of Ti and Al powders (Appel et al., 2011). With increasing temperature to $1250{ }^{\circ} \mathrm{C}$, TiAl and $\mathrm{Ti}_{3} \mathrm{Al}$ phases disappear but Al-rich regions are still present (Figure 6). When the isothermal holding time at $1250{ }^{\circ} \mathrm{C}$ is increased to 5', no Al-rich regions were present anymore indicating that a homogeneous $\mathrm{Al}$ distribution was achieved (Figure 6). 

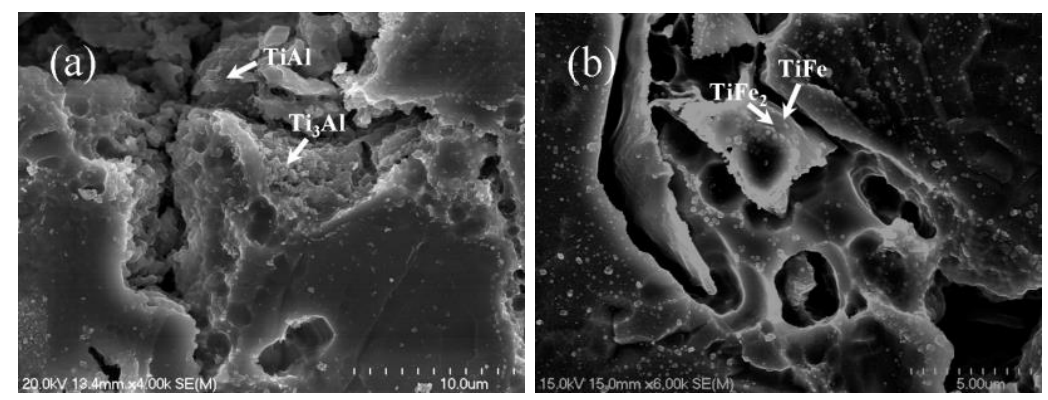

Figure 8. Details of the phases constituting the Al-rich (a) and Fe-rich (b) regions of the Ti-5Al-2.5Fe alloy reactive induction sintered at $700{ }^{\circ} \mathrm{C}$.

In the $\mathrm{Ti}-\mathrm{Fe}$ phase diagram, $\mathrm{TiFe}$ and $\mathrm{TiFe}_{2}$ are the two equilibrium intermetallic phases. It has been reported that $\mathrm{TiFe}$ and $\mathrm{TiFe}_{2}$ intermetallics can be present in the reaction region in diffusion bonded $\mathrm{Ti}$ and 304 stainless steel (Ghosh et al., 2003; Kundu et al., 2005). However only the eutectoid TiFe phase formed at $1085^{\circ} \mathrm{C}$ was detected when Fe was added to $\mathrm{Ti}$ (Liu et al., 2006). Furthermore, it was reported that $\mathrm{TiFe}$ and $\mathrm{TiFe}_{2}$ intermetallics were not present in the Ti-5Al-2.5Fe alloy made from elemental powders and vacuum sintered for 2 hours at temperatures ranging from $700-1400^{\circ} \mathrm{C}$ (Siqueira et al., 2009). Conversely, in the current study Fe-rich regions consisting of a core of pure iron were observed in the powder compacts sintered at $700{ }^{\circ} \mathrm{C}$. Around the core of pure iron, $\mathrm{TiFe}$ and $\mathrm{TiFe}_{2}$ phases were identified by EDS as shown in Figure $8 \mathrm{~b}$ ). So by heating the powder compact to $700{ }^{\circ} \mathrm{C}$, the heat energy released by the exothermic reaction between $\mathrm{Ti}$ and $\mathrm{Al}$ induced the $\mathrm{Fe}$ and $\mathrm{Ti}$ powders to form $\mathrm{TiFe}$ and $\mathrm{TiFe}_{2}$ phases. However, this could not be detected either via DTA or XRD analysis. With increasing sintering temperature to $1250{ }^{\circ} \mathrm{C}$ without any isothermal holding, the $\mathrm{Fe}, \mathrm{TiFe}$ and $\mathrm{TiFe}_{2}$ phases dissolved and a homogeneous $\mathrm{Fe}$ distribution was obtained (Figure 6). Overall, a homogeneous distribution of Ti, Al and $\mathrm{Fe}$ in the sintered materials was achieved after 5 minutes of isothermal holding at $1250{ }^{\circ} \mathrm{C}$ resulting in the typical Widmanstätten microstructure. Comparing the 
diffusivity of Al and Fe on Ti (Gerold and Herzig, 1997; Shevchuk, 2004), the interdiffusion coefficient of the latter is 10 times larger than that of the former at 1250 ${ }^{\circ} \mathrm{C}$. This justifies the finding that an additional 5 minutes isothermal holding at 1250 ${ }^{\circ} \mathrm{C}$ is required to achieve a completely homogeneous distribution of $\mathrm{Al}$.

\subsection{Effect of microstructure and porosity on the mechanical behaviour of the reactive induction sintered $\mathrm{Ti}-5 \mathrm{Al}-2.5 \mathrm{Fe}$ alloy}

With the sintering condition studied, the reactive induction sintered Ti-5 Al-2.5Fe alloy has a porosity of $7.9-12.4 \%$ and thus a large amount of interconnected pores which significantly affect the fracture mode. Regardless of the homogeneity of microstructure, the properties of the reactive induction sintered Ti-5Al-2.5Fe alloy are dependent on the sintering necks between the powder particles crated during sintering. The plane porosity was defined by Slesar et al (Slesar et al., 1987) to accurately evaluate the effect of pores on properties. Furthermore, the load-bearing cross section of each reactive induction sintered Ti-5Al-2.5Fe alloy was calculated from plane porosity (Chang and Zhao, 2013; Danninger et al., 2015) and it was found that it increases gradually from $15.3 \%$ in the powder compact sintered at $700{ }^{\circ} \mathrm{C}$ to $57.0 \%$ in the powder compact sintered at $1250{ }^{\circ} \mathrm{C}$ with a holding time of $15^{\prime}$ (Figure 9 a). Therefore, the tensile strength of reactive induction sintered Ti-5Al-2.5Fe alloy increases along with the load-bearing cross section (Figure 9 b). Consequently, the fracture mode of the reactive induction sintered Ti-5Al-2.5Fe alloy changes from cleavage to ductile dimples pattern, in agreement with the literature (Chang and Zhao, 2013). 

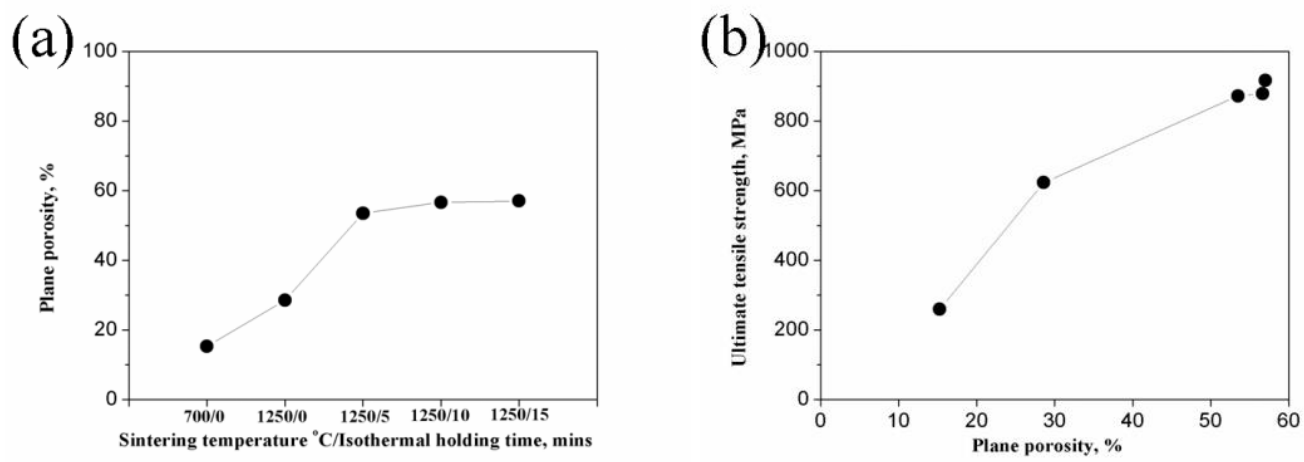

Figure 9. Variation of the load-bearing cross section with the processing parameters (a) and relationship between ultimate tensile strength and load-bearing cross section (b) of the reactive induction sintered Ti-5Al-2.5Fe alloy.

Once a fully homogeneous microstructure is obtained (i.e. $1250{ }^{\circ} \mathrm{C} / 5^{\prime}$ ), both the residual porosity and the microstructure affect the mechanical properties where for the tensile properties the pores can be considered as defect and the $\alpha+\beta$ colony size of the Widmanstätten microstructure determines the effective slip length as in other alphabeta Ti alloys (Lütjering and Williams, 2003). For that the dependence of the average $\alpha+\beta$ colony size with the isothermal holding time was quantified and the results are presented in Figure 10 showing that there is no significant variation and thus indicating that, under the conditions studied, the growth of $\alpha+\beta$ colonies during induction sintering is limited. This is because any residual pore at colony boundaries has a pinning effect that contributes towards reducing the mobility of grain and colony boundaries (Kang, 2004). It is then inferred that for the reactive induction sintered Ti-5Al-2.5Fe alloy, the slight differences in microstructure have little effect on the tensile properties of the material and thus the tensile properties are mainly dependent on the features of the residual pores as demonstrates via the use of the plane porosity. 


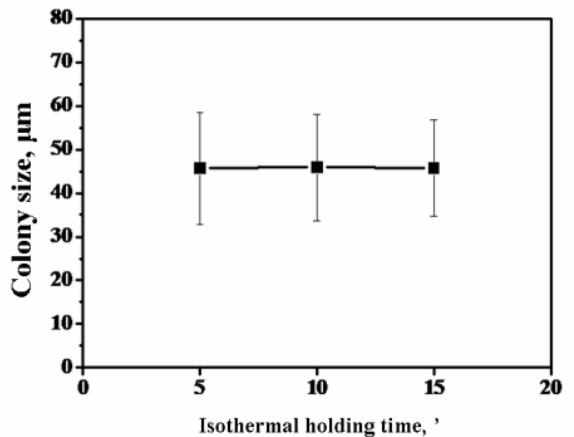

Figure 10. Variation of the $\alpha+\beta$ colony size with the holding time of the Ti-5 $\mathrm{Al}-2.5 \mathrm{Fe}$ alloy reactive induction sintered at $1250{ }^{\circ} \mathrm{C}$.

It is worth mentioning that, in spite of the presence of the residual pores, the ultimate tensile strength of the sintered alloy at $1250{ }^{\circ} \mathrm{C}$ with a holding time of 15 ' (i.e. 916 $\mathrm{MPa}$ ) is higher than that of the wrought alloy (i.e. $900 \mathrm{MPa}$ ) (Welsch et al., 1993). On average the reactive induction sintered Ti-5Al-2.5Fe alloy has an oxygen content of $0.43 \%$ and nitrogen continent of $0.01 \%$ which are, respectively, higher and lower than the limits specified for the wrought counterpart (O: $0.2 \%$ and $\mathrm{N}: 0.03 \%)$. The reactive induction sintered Ti-5Al-2.5Fe alloy shows also some elongation to fracture (Figure 7 a), which in this case is strictly dependent on the residual porosity, regardless of the homogeneity of microstructure. Since the porosity in the sintered Ti-5Al-2.5Fe alloy decreases by either increasing the sintering temperature from $700{ }^{\circ} \mathrm{C}$ to $1250{ }^{\circ} \mathrm{C}$ or the holding time from 0 to $15^{\prime}$, the ductility should increase consequently. Moreover, the decrement of the residual porosity is commonly coupled with the simultaneous rounding and coalescence of the residual pores (Figure 2), which have two counteracting effects. Pore rounding would reduce the stress concentration factor of the residual pores, leading to higher ductility, but coarser pores would be more detrimental for the ductility of the material. Therefore, to accurately evaluate the effect of the residual pores on the elongation to fracture of the sintered $\mathrm{Ti}-5 \mathrm{Al}-2.5 \mathrm{Fe}$ 
alloy, the plane porosity was considered. It is found that the elongation to fracture of sintered Ti-5Al-2.5Fe alloy is increased by decreasing the plane porosity (i.e. increasing the load-bearing cross section).

\section{Conclusions}

In this study reaction induction sintering was used to manufacture the alpha-beta Ti5Al-2.5Fe alloy using elemental $\mathrm{Ti}, \mathrm{Al}$ and $\mathrm{Fe}$ powders and the effect of the sintering parameters was assessed. The following conclusions can then be drawn:

1. Reactive induction sintering can be used to manufacture blended elemental $\mathrm{Ti}$ alloys for non-critical applications significantly reducing the processing time and thus the final cost of the alloy;

2. It is proven that transient Al- or Fe-based intermetallic phases are formed during heating of the compacts leading to some swelling. Nevertheless, under appropriate minimum sintering conditions such as $1250{ }^{\circ} \mathrm{C}$ with a $5^{\prime}$ these transient phases are completely dissolved and do not negatively influence the mechanical behaviour of the material;

3. A homogeneous elemental distribution and a completely Widmanstätten microstructure were obtained in Ti-5Al-2.5Fe powder compacts sintered at 1250 ${ }^{\circ} \mathrm{C} / 5$ '. A further increase in the isothermal holding time gives a homogeneous elemental distribution and the $\alpha+\beta$ colonies in the Widmanstätten microstructure did not show significant growth.

4. The tensile strength and elongation to fracture of sintered the Ti-5Al-2.5Fe alloy significantly increase when increasing the sintering temperature or the isothermal holding time. The mechanical behaviour of the reactive induction sintered alloy is strongly dependent on the plane porosity left by the sintered process. 


\section{Acknowledgements}

This work was supported by the New Zealand Ministry of Business, Innovation and Employment (MBIE) through the UOWX1402 research contract.

\section{References}

Abkowitz, S., Abkowitz, S., Fisher, H., 2011. Breakthrough claimed for titanium PM. Metal Powder Report 66, 16-21.

Appel, F., Paul, J.D.H., Oehring, M., 2011. Gamma titanium aluminide alloys: science and technology. John Wiley \& Sons.

Böhm, A., Scholl, R., Kieback, B., 2001. Reaction Sintering of Components from yTiAI-Based Alloys, In: G. Kneringer, P.R.a.H.W. (Ed.), 15" International Plansee Seminar.

Çavdar, U., Atik, E., 2014. Investigation of conventional-and induction-sintered iron and iron-based powder metal compacts. Jom 66, 1027-1034.

Chang, I., Zhao, Y., 2013. Advances in powder metallurgy: Properties, processing and applications. Elsevier.

Choubey, A., Balasubramaniam, R., Basu, B., 2004. Effect of replacement of V by Nb and $\mathrm{Fe}$ on the electrochemical and corrosion behavior of Ti-6Al-4V in simulated physiological environment. Journal of Alloys and Compounds 381, 288-294.

Danninger, H., Weiss, B., Betzwar-Kotas, A., Khatibi, G., Sohar, C., Dlapka, M., Gierl-Mayer, C., 2015. FATIGUE RESPONSE AND FRACTOGRAPHY OF SINTERED MATERIALS. Powder Metallurgy Progress 15, 218.

Dewidar, M., 2010. Microstructure and mechanical properties of biocompatible high density Ti-6Al-4V/W produced by high frequency induction heating sintering. Mater. Des. 31, 3964-3970.

Donachie, M.J., 2000. Titanium: a technical guide. ASM international.

Froes, F., Mashl, S., Hebeisen, J., Moxson, V., Duz, V., 2004. The technologies of titanium powder metallurgy. JOM 56, 46-48.

Fujita, T., Ogawa, A., Ouchi, C., Tajima, H., 1996. Microstructure and properties of titanium alloy produced in the newly developed blended elemental powder metallurgy process. Materials Science and Engineering: A 213, 148-153.

German, R.M., 1996. Sintering theory and practice. Solar-Terrestrial Physics (Solnechno-zemnaya fizika), 568.

Gerold, U., Herzig, C., 1997. Titanium Self-Diffusion and Chemical Difffusion in bcc Ti-Al Alloys, Defect and Diffusion Forum. Trans Tech Publ, pp. 437-442.

Ghosh, M., Bhanumurthy, K., Kale, G., Krishnan, J., Chatterjee, S., 2003. Diffusion bonding of titanium to 304 stainless steel. Journal of Nuclear Materials 322, 235-241.

Henriques, V., Sandim, H., Coelho, G., da Silva, C., 2003. Microstructural evolution during hot pressing of the blended elemental $\mathrm{Ti}-6 \% \mathrm{Al}-7 \% \mathrm{Nb}$ alloy. Materials Science and Engineering: A 347, 315-324.

Hermel, W., Leitner, G., Krumphold, R., 1980. Review of induction sintering: fundamentals and applications. Powder Metallurgy 23, 130-135. 
Jia, M., Gabbitas, B., 2015. Rapid Synthesis of a Near- $\beta$ Titanium Alloy by Blended Elemental Powder Metallurgy (BEPM) with Induction Sintering. Metallurgical and materials transactions A 46, 4716-4729.

Kang, S.-J.L., 2004. Sintering: densification, grain growth and microstructure. Butterworth-Heinemann.

Kim, H.-C., Kim, D.-K., Woo, K.-D., Ko, I.-Y., Shon, I.-J., 2008. Consolidation of binderless WC-TiC by high frequency induction heating sintering. International Journal of Refractory Metals and Hard Materials 26, 48-54.

Krumphold, R., Hemel, W., Leitner, G., 1984. Short-Time Induction Sintering of FeBased Materials and Hardmetals. Elsevier Science, 127-138.

Kundu, S., Ghosh, M., Laik, A., Bhanumurthy, K., Kale, G., Chatterjee, S., 2005. Diffusion bonding of commercially pure titanium to 304 stainless steel using copper interlayer. Materials Science and Engineering: A 407, 154-160.

Lee, C., 1998. The effect of heating rate on the reactive sintering of $\mathrm{Ti}-48 \% \mathrm{Al}$ elemental powder mixture. Journal of materials science letters 17, 1367-1370.

Liu, Y., Chen, L., Tang, H., Liu, C.T., Liu, B., Huang, B., 2006. Design of powder metallurgy titanium alloys and composites. Materials Science and Engineering: A 418, 25-35.

Luo, J.-G., Acoff, V.L., 2004. Using cold roll bonding and annealing to process Ti/Al multi-layered composites from elemental foils. Materials Science and Engineering: A 379, 164-172.

Luo, S., Yan, M., Schaffer, G., Qian, M., 2011. Sintering of titanium in vacuum by microwave radiation. Metall. Mater. Trans. A 42, 2466-2474.

Lütjering, G., Williams, J.C., 2003. Titanium. Springer.

Mirjalili, M., Soltanieh, M., Matsuura, K., Ohno, M., 2013. On the kinetics of TiAl 3 intermetallic layer formation in the titanium and aluminum diffusion couple. Intermetallics 32, 297-302.

Murr, L., Quinones, S., Gaytan, S., Lopez, M., Rodela, A., Martinez, E., Hernandez, D., Martinez, E., Medina, F., Wicker, R., 2009. Microstructure and mechanical behavior of Ti-6Al-4V produced by rapid-layer manufacturing, for biomedical applications. Journal of the mechanical behavior of biomedical materials 2, 20-32.

Murray, J.L., 1988. Calculation of the titanium-aluminum phase diagram. Metallurgical Transactions A 19, 243-247.

Niinomi, M., 1998. Mechanical properties of biomedical titanium alloys. Materials Science and Engineering: A 243, 231-236.

Niinomi, M., 2002. Recent metallic materials for biomedical applications. Metallurgical and materials transactions A 33, 477-486.

Niinomi, M., Kobayashi, T., Toriyama, O., Kawakami, N., Ishida, Y., Matsuyama, Y., 1996. Fracture characteristics, microstructure, and tissue reaction of Ti-5Al-2.5 Fe for orthopedic surgery. Metallurgical and Materials Transactions A 27, 3925-3935.

Paul, A., Laurila, T., Vuorinen, V., Divinski, S.V., 2014. Thermodynamics, diffusion and the Kirkendall effect in solids. Springer.

Paul, A., Van Dal, M., Kodentsov, A., Van Loo, F., 2004. The Kirkendall effect in multiphase diffusion. Acta Materialia 52, 623-630.

Salak, A., Leitner, G., Hermel, W., 1981. Properties of Induction-Sintered Fe--Mn--C and Fe--Mn--Cu--C Steel in the Sintered and Forged States. Powder Metall. Int. 13, 21-24.

Savitskii, A.P., 2009. Sintering of systems with interacting components. Materials Science Foundations 57. 
Shevchuk, Y.A., 2004. Interdiffusion in the $\beta$ Phases of the Ti-Ni and Ti-Fe Systems. Inorganic materials 40, 376-379.

Shon, I.-J., Jeong, I.-K., Ko, I.-Y., Doh, J.-M., Woo, K.-D., 2009. Sintering behavior and mechanical properties of $\mathrm{WC}-10 \mathrm{Co}, \mathrm{WC}-10 \mathrm{Ni}$ and $\mathrm{WC}-10 \mathrm{Fe}$ hard materials produced by high-frequency induction heated sintering. Ceramics International 35, 339-344.

Shon, I.-J., Kim, B.-R., Doh, J.-M., Yoon, J.-K., 2010. Consolidation of binderless nanostructured titanium carbide by high-frequency induction heated sintering. Ceramics International 36, 1797-1803.

Shon, I.-J., Lee, G.-W., Doh, J.-M., Yoon, J.-K., 2013. Effect of milling on properties and consolidation of $\mathrm{TiO} 2$ by high-frequency induction heated sintering. Electronic Materials Letters 9, 219-225.

Simchi, A., Danninger, H., 2000. Electrical conductivity and microstructure of sintered ferrous materials: sintered iron. Powder Metallurgy 43, 209-218.

Siqueira, R., Sandim, H., Hayama, A., Henriques, V., 2009. Microstructural evolution during sintering of the blended elemental Ti-5Al-2.5 Fe alloy. Journal of Alloys and Compounds 476, 130-137.

Slesar, M., Dudrova, E., Parilak, L., Besterci, M., Rudnayova, E., 1987. Influence of pressing and sintering conditions on microstructure formation of metallic porous systems. Sci. Sintering 19, 17-30.

Sujata, M., Bhargava, S., Sangal, S., 1997. On the formation of TiAl3 during reaction between solid Ti and liquid Al. Journal of materials science letters 16, 1175-1178.

Sun, Y., Haley, J., Kulkarni, K., Aindow, M., Sachdev, A., Lavernia, E., 2015. Influence of electric current on microstructure evolution in Ti/Al and Ti/TiAl 3 during spark plasma sintering. Journal of Alloys and Compounds 648, 1097-1103.

Wei, W., Liu, Y., Zhou, K., Huang, B., 2003. Effect of Fe addition on sintering behaviour of titanium powder. Powder metallurgy 46, 246-250.

Welham, N., 1998. Mechanical activation of the solid-state reaction between $\mathrm{Al}$ and TiO 2. Materials Science and Engineering: A 255, 81-89.

Welsch, G., Boyer, R., Collings, E., 1993. Materials properties handbook: titanium alloys. ASM international.

Wenbin, F., Lianxi, H., Wenxiong, H., Erde, W., Xiaoqing, L., 2005. Microstructure and properties of a TiAl alloy prepared by mechanical milling and subsequent reactive sintering. Materials Science and Engineering: A 403, 186-190.

Xu, L., Cui, Y., Hao, Y., Yang, R., 2006. Growth of intermetallic layer in multilaminated Ti/Al diffusion couples. Materials Science and Engineering: A 435, 638647.

Zadra, M., Casari, F., Girardini, L., Molinari, A., 2008. Microstructure and mechanical properties of cp-titanium produced by spark plasma sintering. Powder Metall. 51, 59-65. 